\title{
Medical Education in Naples, Italy, at the Time of SARS-CoV-2
}

\author{
Gianluca Pagano, ${ }^{1}$ Gaetano Luglio. ${ }^{2}$
}

\section{The Experience}

Lockdown, quarantine. These are the key words on top of our agendas in Italy and in the most part of the world during these difficult times. The spread of an invisible airways invader has dramatically changed our daytime routine and is affecting social dynamics in their entirety. As part of our everyday life, medical education has been remarkably involved too. Here below we will discuss about our experience, the one of a final-year medical student who is about to be remembered as one of the "Coronavirus-generation graduates" and of a young assistant professor of Surgery.

During the last three years of their long road to graduation, medical students are involved into both surgical and clinical internships not only to achieve exams credits but specially to work on their final thesis. In fact, they are able to choose a specific medical area in which focusing their effort. Due to safety restrictions, medical students are now suspended from attending their internship. As well as students' clinical/surgical activities, scientific research has been slowed down too. As far as our experience is concerned, this is the case of some observational studies promoted by nation- and Europe-wide collaborative groups which are now, reasonably, suspended. ${ }^{2,3}$

The way of teaching has temporarily changed as classic live face to face lessons have been replaced by streaming ones via Microsoft Teams $®$ (MT), a very useful software in educational and smart-working systems, as shown in Figure 1 and Figure 2. However, we think that this unfortunate calamity pushed us to get familiar with the online teaching, something we were not used to take into proper consideration.

Moreover, lessons can be recorded upon teachers consent in order to have them available for further review and listening; tests will be remotely performed on line, which will grant increased transparency especially as far the oral ones.

As a matter of fact, MT platform allow students to interact more efficiently with teachers when compared to classic lessons: teachers found a greater number of questions asked during the online ones, perhaps dictated by the fact that, being the lesson online, that feeling of embarrassment in asking an oral question in a class was diminished. From this perspective, MT is a teaching resource perfectly mirroring our social-era relationships where human warm is kind of lost but we are more confident in voicing our feelings through a keyboard and beyond a screen.

By contrast, we urge to stress out that online classes will never be able to replace clinical practice which has to be taught and learned at the patient's bed, visiting and touching him.

But now six years have passed. For a medical student this means that he/she is about to achieve his/her long-life goal: graduation. Never in
Figure 1. Online General Surgery focus with Professor Luglio and his Graduate Students.

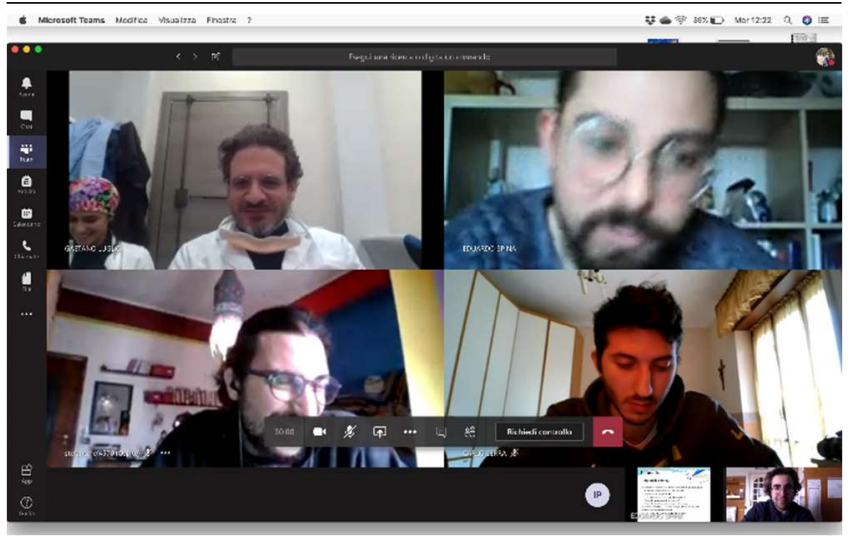

Figure 2. Live Face-to-Face Lesson at the School of Medicine and Surgery, Federico II University of Naples, Italy.

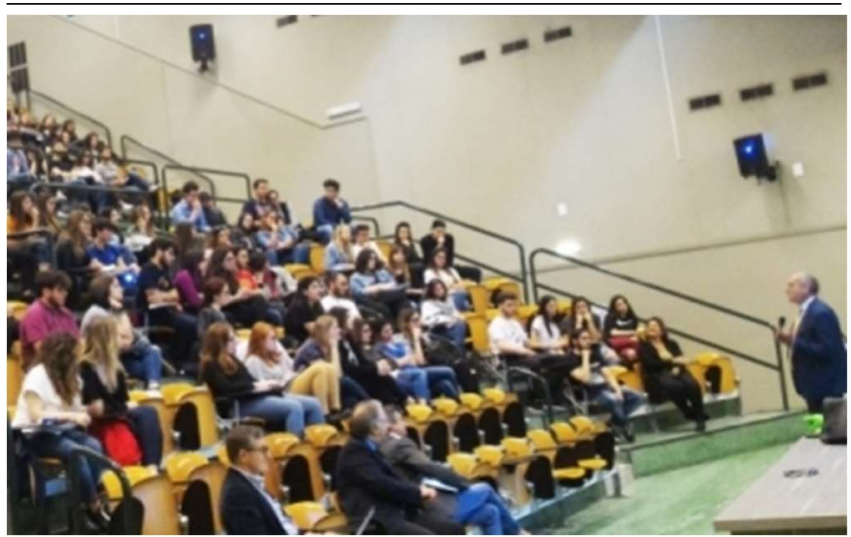

their lives would they have imagined the graduation ceremony to be telematic. In fact, both the discussion of the final thesis work and the graduation announcement will be made via MT. Graduation Evaluation Commission members will be joining candidates in a conference videocall in which each student will show the results of their studies. At the end of the last discussion, there will be the official graduation proclamation. Both professors and students will participate from their homes/offices (Figure 3). As it may be clear, during the graduation day there will not be any public or private celebration for this once-in-alifetime achievement. In line with other Italian universities policy, the Rector of Federico II University of Naples, in Italy, assured that an official ceremony will be held once this emergency status is over.

\footnotetext{
MD, University of Naples Federico II, Italy

2 Assistant Professor of Surgery, University of Naples Federico II, Italy
}

About the Author: Gianluca Pagano is a young Medical Doctor graduated at the University of Naples Federico II with the highest marks, during the SARS-CoV-2 pandemic. His area of interest is Colorectal Surgery, in particular IBD surgery and surgical oncology. 


\section{Experience}

Figure 3. A Brand-new Graduate in Medicine and Surgery at Federico II University of Naples, Italy.

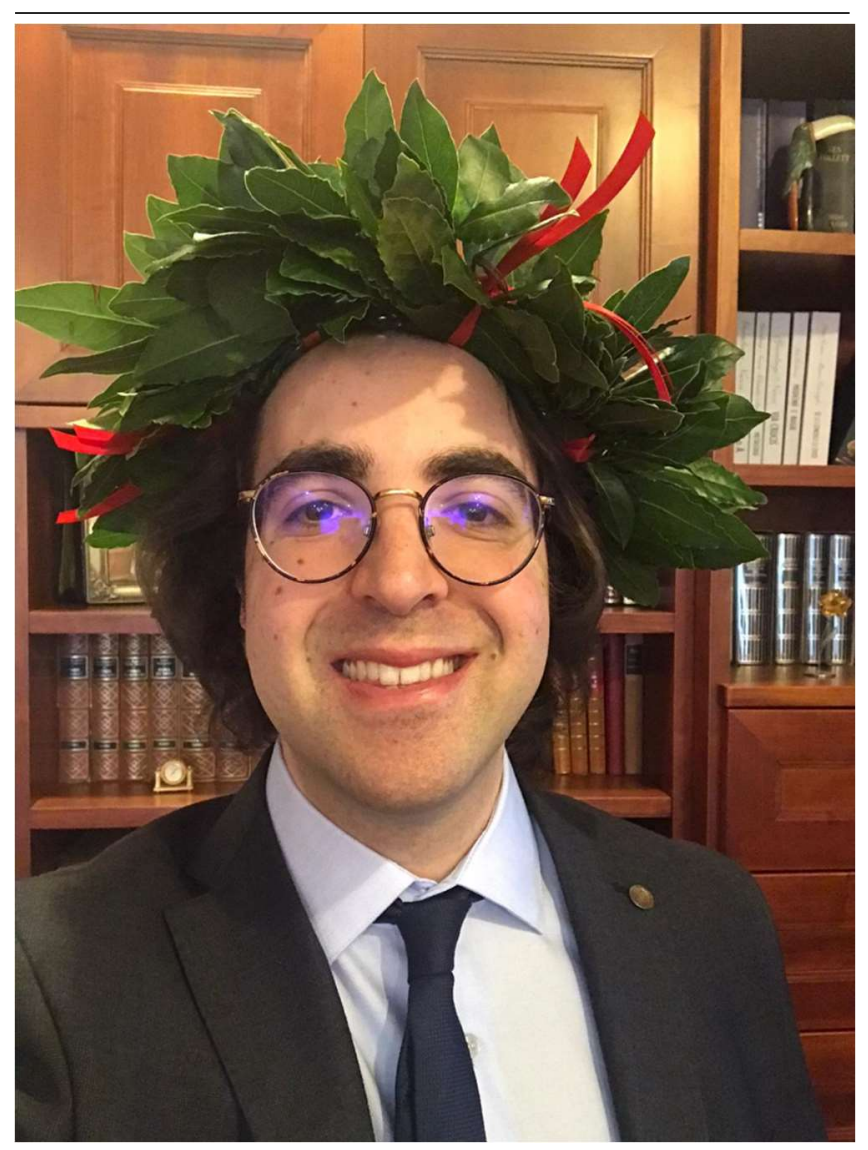

Often, during the years of a student's internship, the professor's role changes: at the beginning he is the academic but, month by month, he becomes a mentor. From this perspective, it is easily understandable how disappointing it could be for him not to be side by side with his pupil in the plenary hall in front of an audience.

It is true, we all are annoyed to live in a limbo but we should keep our feelings under control. People are suffering, are dying, are losing their jobs. Then, let's stay home as we are not stuck but just safe. 


\section{References}

1. Sun P, Lu X, Xu C, Sun W, Pan B. Understanding of COVID-19 based on current evidence. J Med Virol. 2020 Feb 25;1-4.

2. Pata F, Pellino G, Bath MF, Nepogodiev D, Pasquali S, Farina V, et al. ItSURG: a challenge for surgical research in Italy. Updates Surg. 2017 Dec;69(4):551-552.
3. Arezzo A, Farina V, Foppa C, Gavagna L, Morino M, Pasquali S, et al. EuroSurg: A new European student-driven research network in surgery. Colorectal Dis. 2016 Feb;18(2):214-5.

\section{Acknowledgments}

None.

Conflict of Interest Statement at Funding

The Authors have no funding, financial relationships or conflicts of interest to disclose.

\section{Author Contributions}

Writing - Original Draft: GP, and CL. Writing - Review At Editing: GP, and CL.

Cite as:

Pagano G, Luglio G. Medical Education in Naples, Italy, at the Time of SARS-CoV-2. Int J Med Students. 2020 Jan-Apr;8(1):51-53

This work is licensed under a Creative Commons Attribution 4.0 International License 